\title{
Renal Presevation: The Cassandra Effect
}

\section{F Catena AD Pinna*}

Department of General, Emergency and Transplant Surgery, St Orsola- Malpighi University Hospital, Italy

Effective and successful renal transplantation depends on a sequence of events relating to the selection of donor, graft preservation, surgical implantation and recipient treatment.

Static Cold storage technique (CS) and Hypothermic Machine Perfusion (HMP) are the most commonly used techniques for kidney preservation.

Since the eighties, the majority of organs are preserved by static cold storage (CS), which is still considered the gold standard in kidney preservation.

CS is the technique according to which the kidney is flushed through immediately, after the procurement, by hydrostatic pressure with a sterile preservation solution.

Consequently, the organ is left in a predisposed plastic bag with the cold perfusion solution. The whole bag is then covered in ice to maintain the temperature between $4-0^{\circ} \mathrm{C}$

In hypothermic machine perfusion, a pump continuously perfuses the kidney with a cold preservation solution.

Immediately after the procurement, the organ is attached to the machine via the renal artery, after a surgical preparation of the kidney that is required to make the seal airtight. Circulation of the perfusate is achieved through a device that generates either a continuous or a pulsatile flow by a peristaltic pump. Through the artery, the kidney is perfused with a hypothermic preservation solution, at a temperature between $0-4^{\circ} \mathrm{C}$, that provides a continuous supply of nutrients with or without oxygen, in order to eliminate toxic substrates and free radicals produced during the ischemic time.

Numerous are the advantages of HMP reported in literature. This method may decrease vasospasm and provide additional parameters such as flow, resistance, temperature and pressure. This allows an evaluation of the organ viability [1], in order to measure approximate ischemic damage and to give an indication of the kidney post-transplant outcome. With HMP it is possible to improve organ quality by using pharmacologic and gene transfer therapies during the perfusion [2]. Moreover, HMP maintains the hemodynamic stimulation on the vasculature of the organ, which plays a critical role in vascular function, under normal physiologic conditions. Wight et al. reported an excellent meta-analysis based on aggregated results of the current literature concerning HMP versus CS, showing a $20 \%$ reduction in DGF in HMP group [3].

Cassandra was the daughter of King Priam: she was said to have had red hair kept in curls, blue eyes, and fair skin; she was very beautiful. She is portrayed as intelligent, charming, desirable, elegant, friendly, and gentle: she was described as the "second most beautiful woman in the world." Cassandra made a promise to Apollo to become his consort, but broke it, thus incurring his wrath: though she has retained the power of foresight, no one will believe her predictions.

In renal preservation for transplantation there is probably a Cassandra effect.

We know that machine perfusion works better than static preservation but only $20 \%$ of US kidneys are preserved with this technique [4].

Which are reasons of this Cassandra effect: probably perfusion machine is less applicable and more expensive.

Because of the great necessity of economical, scientific and logistic efforts to eventually introduce this kind of perfusion on a large scale, it necessitates to be more deeply understood and scientifically proved to be more effective than standard procedures.

Therefore, it is to be kept in mind that every innovation regarding the organ preservation matter has to face this Cassandra effect in the scientific community: for this reason, a great effort shall be done to improve the quality of scientific based evidence, in order to determine the best way to preserve organs destined for transplant.

\section{References}

1. Moers C, Smits JM, Maathuis MH, Treckmann J, Gelder F, et al. (2009) Machine perfusion or cold storage in deceased-donors kidney transplantation. N Engl J Med 2009 360: 7-19.

2. Schold JD, Kaplan B, Howard RJ, Reed Al, Foley DP, et al. (2005) Are we frozen in time? Analysis of the utilization and efficacy of pulsatile perfusion in renal transplantation. Am J Transplant 5: 1681-1688.

3. Wight JP, Chilcott JB, Holmes MW, Brewer N (2003) Pulsatile machine perfusion vs. cold storage of kidneys for transplantation: a rapid and systematic review. Clin Transplant 17: 293-307.

4. Taylor MJ, Baicu SC (2010) Current state of hypothermic machine perfusion preservation of organs: The clinical perspective. Cryobiology 60: S20-35.
*Corresponding author: F Catena AD Pinna, Dept of General, Emergency and Transplant Surgery, St Orsola- Malpighi University Hospital, Italy, E-mail: faustocatena@gmail.com

Received August 22, 2013; Accepted August 22, 2013; Published August 26, 2013

Citation: Pinna FCAD (2013) Renal Presevation: The Cassandra Effect. J Transplant Technol Res 3: e121. doi:10.4172/2161-0991.1000e121

Copyright: (c) 2013 Pinna FCAD. This is an open-access article distributed under the terms of the Creative Commons Attribution License, which permits unrestricted use, distribution, and reproduction in any medium, provided the original author and source are credited. 